\title{
Study On the Condition and Reasons for College Students Cheating and Effective Control Methods- Based on the Calculation of SPSS Software
}

\author{
Fengyin $\mathrm{Li}^{1, \mathrm{a}^{*}}$ and Li Feng ${ }^{2, \mathrm{~b}}$ \\ ${ }^{1}$ Bohai university ,jinzhou Liaoning province, Liaoning province, China \\ ${ }^{2}$ Senior high school attached to Bohai University, Liaoning province, China \\ alifengyingch@126.com, b1683439041@qq.com \\ *The Corresponding author
}

Keywords: College students; Exam cheating; Control Methods

\begin{abstract}
Nowadays, the quality of education in China has improved a lot. However, some details cannot be ignored during the process while education is developing rapidly. In the meanwhile, with the development of higher education, the phenomenon of college students cheating emerges. However, the cheating phenomenon is still rampant despite strict measures carrie out by schools. Some students still cheat on exams even though they know how serious it will be if they get caught. It is not only because of students themselves, but also related to school management and social morality. Therefore, in this paper, we will mainly adopt questionnaire survey method along with interview as well as literatures to analyze the reasons of college students cheating problem from three perspectives of society, school and individuals. Based on this, we are going to come up with effective control methods, which are beneficial to help students to understand the phenomenon as well as its reasons and control methods, and are problems we have to focus on in the higher education field.
\end{abstract}

\section{Problem Raising}

Research Goals. This paper is going to analyze the college students cheating problem from the perspectives of society, schools and individuals so as to come up with some solutions. At the same time, this paper hopes that the phenomenon can be completely eradicate. Finally, we hope that there will be good academic atmosphere and the education quality will be improved so that honest and high-quality students will be cultivated.

Research Hypothesis. In the author's opinion, the reasons for college students cheating is because of society, schools and individuals. Therefore, we are going to send out questionnaires to students in Bahai university so as to understand the reasons.

So, the hypothesis is that there are different reasons for students to cheat.

\section{Research Process}

First of all, in order to determine the topics of this questionnaire to initially understand the reasons for students to cheat, we will adopt interview methods. We are going to interview three males and three females (among which each boy and girl are from arts, science, and sports) and the interview time is about 6-7 minutes. The interview contents include: (1) do you feel study stress? (2) is the exam difficult? (3) do you ever think about being appraised? (4) do you have cheating problems around you? how do you judge? (5) why do you think the reasons for cheating? 
This paper is going to mainly adopt questionnaires, which is designed from the perspectives of social structure and culture, including social dimension, school dimension, and individual dimension. What's more, it will cover 18 general questions, 2 polygraph tests, 3 questions to explore cheating problem. Furthermore, it will be divided into quantitative and multiple choices. Among which, the social dimension includes: new technology impact, social environment, lagging education philosophy and law system. School dimension includes: school exam atmosphere, school management (re-study system, punishment rules and hardware equipment), exam item value, monitor exam etc. Individual dimension includes: individual quality as well as morality, learning passion, benefits-driven (be appraised or high grades), subjects difference, preparation difference, emotional feelings (buddy relation) etc.

Finally, the literature can be seen between the lines. Before designing this questionnaire, the author refers to relative literatures (see bibliography) to determine the dimension and topic setting, which can compensate for the shortages of the questionnaire and can play a pivotal role in making this questionnaire. While summarizing the result and come up with suggestions, the author also refers to relevant literatures (see bibliography).

\section{Research Results}

Demography Information of Respondents. In those valid recycled questionnaires, respondents include 48 students from sophomore year, occupying $27.7 \%$ and 71 students from junior year, occupying $41.0 \%$, and 54 students from senior students, occupying $31.2 \%$. Due to the approaching of graduation, there are few students from senior year and sophomore year students have a busy schedule, so the main respondents are junior year students.

The difference of female and male students is not obvious. There are 85 male students, occupying $49.1 \%$ and 88 female students, occupying $50.9 \%$, and the difference rate is less $1 \%$. Therefore, we can conclude that the female and male rate is even.

Among the respondents, there are 77 students from science, occupying 44.5\%; 69 students from arts, occupying 39.9\%; 27 students from sports, occupying 15.6\%. Therefore, we can conclude that the sincere and arts rate is even and there are not many students from sports.

\section{Reliability Analysis.}

Table 1 Reliability Statistics

\begin{tabular}{|l|l|}
\hline Cronbach's Alpha & N of Items \\
\hline .790 & 23 \\
\hline
\end{tabular}

Figure $1-4$

Reliability and validity test:

Reliability test is going to confirm the consistency as well as the stability. (Note: Reliability $>0.70$ proves effectiveness ). Revealed by the data via SPSS, we can find out that the reliability is 0.790 , which is more than 0.70 . Therefore, we can conclude that it is an effective questionnaire and is worth being studied.

Validity is to accurately test the features, or simply we can say the accuracy or usefulness. However, the validity is not mentioned in literature and we are not familiar with SPSS technology, so calculation cannot be conducted well.

The Alpha value of these 21 questions is 0.790 with good reliability and we can continue to analyze. 
Frequency Analysis. Based on the code and record of 173 valid questionnaires, we can get the following three dimensions based on SPSS software analysis:

The first dimension, society dimension includes: new technology impact (three questions); society atmosphere (four questions); lagging education philosophy (family and society competition) No.11 and 16; law system (seven questions).

Table 23 The emergence of high-tech cheating tools encourages students to cheat

\begin{tabular}{|l|l|l|l|l|l|}
\hline \multicolumn{2}{|c|}{} & Frequency & Percent & Valid Percent & $\begin{array}{l}\text { Cumulative } \\
\text { Percent }\end{array}$ \\
\hline \multirow{7}{*}{ Valid } & $\begin{array}{l}\text { Strongly } \\
\text { disagree }\end{array}$ & 6 & 3.5 & 3.5 & 3.5 \\
\cline { 2 - 6 } & Disagree & 25 & 14.5 & 14.5 & 17.9 \\
\cline { 2 - 6 } & Neutral & 53 & 30.6 & 30.6 & 48.6 \\
\cline { 2 - 6 } & Agree & 64 & 37.0 & 37.0 & 85.5 \\
\cline { 2 - 6 } & $\begin{array}{l}\text { Strongly } \\
\text { agree }\end{array}$ & 25 & 14.5 & 14.5 & 100.0 \\
\cline { 2 - 6 } & Total & 173 & 100.0 & 100.0 & \\
\hline
\end{tabular}

Concerning the concept that the emergence of high-teach cheating tools will encourage students to cheat, $51.5 \%$ people agree with it while $17.5 \%$ people disagree with it and other people hold a neutral idea. Technology is a double-edged sword, which is validated in our life. Technology cannot only improve people's work efficiency but also enrich people's resources. However, once technology is used by benefits-driven individuals, they will bring about bad effects on the society. High-tech cheating tools including mobile phone, wireless receiver have replaced traditional paper copying. Moreover, they are convenient and difficult to find.

Table 311 Parents' expectation (being merit students) let students cheat

\begin{tabular}{|l|l|l|l|l|l|}
\hline \multicolumn{2}{|c|}{} & Frequency & Percent & Valid Percent & $\begin{array}{l}\text { Cumulative } \\
\text { Percent }\end{array}$ \\
\hline \multirow{7}{*}{ Valid } & $\begin{array}{l}\text { Strongly } \\
\text { disagree }\end{array}$ & 20 & 11.6 & 11.6 & 11.6 \\
\cline { 2 - 6 } & Disagree & 36 & 20.8 & 20.8 & 32.4 \\
\cline { 2 - 6 } & Neutral & 65 & 37.6 & 37.6 & 69.9 \\
\cline { 2 - 6 } & Agree & 32 & 18.5 & 18.5 & 88.4 \\
\cline { 2 - 6 } & $\begin{array}{l}\text { Strongly } \\
\text { agree }\end{array}$ & 20 & 11.6 & 11.6 & 100.0 \\
\cline { 2 - 6 } & Total & 173 & 100.0 & 100.0 & \\
\hline
\end{tabular}

Concerning the idea that parents' expectation urges students to cheat, $40.1 \%$ people agree while $31.6 \%$ disagree and other people hold a neutral idea. Theoretically speaking, all parents hope their children to grow up healthily and happily. However, some of them want their children to shine out. Therefore, students get a lot of pressure from that traditional idea.

Concerning the idea that the society highly appreciate the high grades makes students to cheat, $56.1 \%$ people agree while $18.5 \%$ disagree and other hold a neutral idea. In the context of current exam system, the idea of picking up the most excellent ones prevails in the society. What's more, 
strict hierarchy urges a mentality of comparing to each other. In order to get high grades, students will disobey the morality to win the feeling of vanity and satisfaction.

After analyzing the 18 bar graphs, we can summarize the following: in the three dimensions, question 3 is related to the society dimension (technology impact), and 4 (social atmosphere); 9 is related to school dimension (school management and re-study system), 23 (teacher supervision); 8 is related to individual dimension (benefits-driven, being appraised), 14 (buddy relation) support rate occupies over $50 \%$. Therefore, we can predict that the above questions are the main causes. Furthermore, more people hold the opposite view concerning the following questions: 11 (lagging education philosophy), 17 (individual quality and morality); concerning the 19 (benefits-driven), the for and against rate is almost the same. So, these three questions cannot be considered as the main causes for cheating.

Therefore, we can conclude the main reasons for students to cheat from the above:

Society dimension: unhealthy society atmosphere; the emergence of high-tech teaching tools urges students to cheat;

School dimension: pressure of re-study system; free and easy supervision urges students to cheat

Individual dimension: parents expectation (being merit students) urge students to cheat; cheating is related to individual quality and behavior.

\section{Solutions}

In the questionnaire, we will set a multiple choice question called effective measures which are beneficial to reduce the cheating with 6 choices. We find out the following: $84.97 \%$ students hold the idea that the exam should be only be confined to close-book ones but also open-book; $64.16 \%$ choose to test the practical ability; $52.60 \%$ students choose to properly adjust the difficulty; $51.44 \%$ students choose to strengthen the moral education; $42.77 \%$ students choose the supervision system should be strengthened; $46.46 \%$ students choose to increase the punishment; $13.78 \%$ students choose other options not mentioned.

The college students cheating problem is not a simple problem and the author comes up with the following suggestions from three perspectives:

From the perspective of society environment and atmosphere:

1. Establish a favorable society environment, cultivate good quality. Increase the social inclusiveness, and don't judge students based on the grades, provide a variety of opportunities for talents good at different things.

2. Through a sound education legal system, strengthen the supervision to remind and restrain the majority of students to abide by their own discipline. Properly punish those cheating to deter others.

3. Strengthen the concept of social education, the formation of family, fair competition. Honesty and fairness should be considered as excellent moral traditions and we have to resist the infiltration of bad culture, actively create excellent social atmosphere.

From the perspective of school management, we can put forward the following solutions:

1. Carry out diversified assessment, comprehensively exam students; Evaluation of merit and membership, degree and diploma is not directly linked with the grades; Establish a scientific and reasonable evaluation system, to stimulate students' interest in learning, and cultivate their learning habits and self-arranged learning ability; University as a place of higher education, is to cultivate all-round talents, so we should not only focus on academic grades but also pay attention to mental health, moral character, physical quality etc. 
2. In addition to knowledge teaching, teachers should also try the utmost to create an interesting classroom so as to improve students' passion and innovative ability; Educators should also update the educational philosophy, advance with times to lead their growth in a healthy way.

3. Ask higher requirement on students, properly increase the frequency of examination, judge the students from multiple examinations to avoid their spot response. For elective courses such as public lessons, open-book examination can be adopted and classroom speech and test will be related to the overall score.

From the perspective of self-discipline:

1. Establish correct values, find out personal value orientation, improve personal integrity and moral cultivation; dilute utilitarian feeling, achieve true self, improve self - moral cultivation; strengthen organizational discipline education ideas, improve the seriousness of cheating.

2. Improve college students' belonging to college courses, and chosen materials should aim to cultivate students' professional knowledge and professional skills. It is difficult to be appropriate for everyone but it is necessary to be good at professional knowledge from the perspective development.

3. Hold an active and healthy attitude while facing the examination without fluky psychology and be brave to know the learning outcomes. While carrying out re-study, they should reflect their own shortcomings and be responsible for their own development.

4. Have the ability to judge without emotional battles. Obey the rules regardless of buddy relation.

\section{References}

[1] Zhu Lei. Overview of the reasons for college students cheating in recent ten years[J]. Youth Studies, 2005(2): 50-52

[2] Wang Cannan. Survey on the reasons for college students cheating [J]. Preclinical Medical Education Edition

[3] Hong Renjie. Reasons and countermeasures for college students cheating [J]. Examination Management, 2004(10): 33-36

[4] Gong Huixiang, Fanjun, Peng Lieping etc. Current condition, psychological reasons and countermeasures for college students cheating[J]. Youth Studies, 1999(2).

[5] Wang Quanbiao, Zhang Lixia. Reasons and countermeasures for college students cheating [J]. University Education Science, 2004(1).

[6] Wei Xiaoqiang, Lu Jinglan. Objectives causes and countermeasures for college students cheating [J]. Journal of Higher Education Management, 2007(1).

[7] Lu Guiping, Chen Long, Wang Xiaoquan etc. Research on the reasons and countermeasures for college students cheating [J]. China Higher Medical Education, 2002(2).

[8] Wu Xiuming. Thoughts on the honesty and credit education of colleges[J]. Journal of Foreign Relations, 2004 (6).

[9] Wang Qinhui. Comprehensively manage exam discipline and strengthen academic performance [J]. Heilongjiang Researches on Higher Education, 2006 (2)

[10]An Yufa, Zheng Peiai, Lu Zhaotong. Reasons and countermeasures for college students cheating $[\mathrm{J}]$. China Agricultural University 